\title{
Optimal low-price guarantees with anchoring
}

\author{
Morten Hviid • Greg Shaffer
}

Received: 18 January 2012 / Accepted: 20 May 2012 / Published online: 13 June 2012

(C) The Author(s) 2012. This article is published with open access at Springerlink.com

\begin{abstract}
Many low-price guarantees are offered by small local firms who compete against much larger rivals. The prices of these larger rivals are often set nationally and thus are independent of local market conditions. Our objective in this paper is to explain why small firms in such environments might nevertheless adopt low-price guarantees. We characterize when offering a low-price guarantee is profitable, and assess which form it should take (i.e., conditional on offering a low-price guarantee, should the small firm offer to match or beat its larger competitor's prices). We also assess the implications thereof (i.e., do the low-price guarantees benefit or harm the small firm's customers).
\end{abstract}

Keywords Price-matching policy $\cdot$ Price-beating policy $\cdot$ Price discrimination

JEL Classification $\mathrm{L} 11 \cdot \mathrm{L} 13 \cdot \mathrm{L} 41$

\footnotetext{
M. Hviid

UEA Law School and ESRC Centre for Competition Policy,

University of East Anglia, Norwich, NR4 7TJ, UK

e-mail: m.hviid@uea.ac.uk

G. Shaffer $(\bowtie)$

Simon School of Business, University of Rochester, Rochester, NY 14627, USA

e-mail: shaffer@simon.rochester.edu

G. Shaffer

Norwich Business School, University of East Anglia, Norwich, NR4 7TJ, UK
} 


\section{Introduction}

Many firms have a "low-price guarantee" policy in which they promise to match or beat any lower price announced by a competitor. Previous studies suggest that these guarantees facilitate implicit price collusion by adversely affecting firms' pricing incentives. In practice, however, many low-price guarantees are offered by small, local firms who compete against much larger rivals. ${ }^{1}$ These larger rivals may or may not be aware of the small firms' prices, and even when they are aware, they may not be able to respond to them if, as is often the case, their pricing decisions are made at the national level. ${ }^{2}$ In these settings, the traditional explanation of low-price guarantees as a means of dampening competition seems unlikely.

Our objective in this paper is to explain why small, local firms might want to adopt low-price guarantees even if they would have no effect on their larger rivals' prices. ${ }^{3}$ Taking the larger rivals' prices as exogeneous, we characterize what form the guarantees should take (i.e., should the firms offer to match or beat their larger rivals' prices), and we assess the implications thereof (i.e., do the guarantees make the firms' customers better or worse off).

Two vignettes help to illustrate the kinds of scenarios we have in mind. Consider first the case of Eddie's Electronics, a local store in southwest Missouri. ${ }^{4}$ It competes against national electronics' chain stores, which sell many of the same branded products. Eddie's is known for its exceptional customer service, and as a result, its prices are on the high end. Should it consider offering a low-price guarantee? Under what conditions? Next, consider the case of Sam's Hardware, also a local store in southwest Missouri. Like Eddie's, Sam's competes primarily against much larger rivals. Unlike Eddie's, however, Sam's is not known for offering good customer service. Its customers tend to be more

\footnotetext{
${ }^{1}$ Using Arbatskaya et al.'s (2004) data, we are able to classify 96 different firms according to whether they are a national chain store, a local chain store (which we define as 10 or fewer stores all located within the same state), an internet-only store, or a store with a single outlet. We find that 63 firms are either a national chain store or an internet-only store, 12 are local chain stores, and 21 are single outlet stores.

${ }^{2}$ Chain stores in the U.K. invariably follow national pricing policies (i.e., they set the same prices in every store regardless of where the store is located). In contrast, local pricing is more common in the U.S., where individual managers may have pricing discretion. However, even in this case, local prices may be constrained by the company's internet sales operations and the prices consumers can obtain on the company's website.

${ }^{3}$ The inspiration for this paper stems from March 2008, when Ocado, a small, high-end UK grocery home shopping business with average orders of 70,000 a week and a single distribution centre, began offering a price-matching guarantee aimed solely at the market leader, Tesco, which serves more than 20 million customers every week and which has a national pricing strategy. We found this to be puzzling because (a) it seemed clear that the usual explanation for low-price guarantees (i.e., that it affects rivals' pricing incentives) did not hold in this case, and (b) Ocado's guarantee could not have been for the purpose of signaling of low prices because Ocado was widely recognized at the time as being considerably more expensive than Tesco.

${ }^{4}$ These are fictional characters, and any resemblance to real firms is unintended and coincidental.
} 
price sensitive on average than those of its larger rivals, and thus, its prices tend to be lower. Should Sam's consider offering a low-price guarantee? If so, should it offer to match or beat its rivals' prices?

One might think that Sam's would have nothing to lose by signaling its lower prices to consumers (either by offering to match or beat prices), and therefore, that adopting a low-price guarantee would always be beneficial for Sam's. ${ }^{5}$ On the other hand, if consumers already know that Sam's prices are lower than its competitors' prices, why bother? In Eddie's case, one might question why Eddie's would ever want to sell for less by offering to match or beat its rivals' lower prices, when it could do so more directly by lowering its own prices.

We suggest that in both cases there are circumstances in which low-price guarantees can profitably be used to segment consumers into those who would avail themselves of the guarantees and those who would not, and that the prices of the chain stores can conveniently serve as anchors against which to enable the discrimination. We also suggest, however, that there are plausible circumstances in which segmenting consumers would not be profitable.

We are not the first to propose that low-price guarantees can be used to segment consumers (see, for example, Png and Hirshleifer 1987), but we are the first, to our knowledge, to explain why (i) price-matching guarantees might sometimes be optimal, (ii) price-beating guarantees might sometimes be optimal, and (iii) no guarantee might sometimes be optimal, all within the same market setting. Our theory makes use of an important stylized fact of the markets we consider, which is that although smaller firms necessarily take into account the prices charged by their larger rivals, the larger firms' prices may be largely independent of the smaller firms' prices (this is particularly true when the larger firms' prices are set nationally). This fact allows the smaller firms to use the larger firms' prices as anchors when setting their own prices and choosing which kinds of low-price guarantees, if any, to offer.

Depending on parameter values, any outcome is possible: one might observe the small firm adopting no guarantee, a price-matching guarantee, or a pricebeating guarantee. In the case of Eddie's Electronics, we find that pricebeating guarantees are optimal (although price-matching guarantees might also be profitable) if the chain-store's price is not much lower; price-matching guarantees are optimal if the chain-store's price is moderately lower (although price-beating guarantees would also be profitable); and no guarantee is optimal if the chain-store's price is much lower. In the case of Sam's Hardware, however, price-beating guarantees are optimal (although price-matching guarantees would also be profitable) if the chain-store's price is not much higher; price-beating guarantees are optimal (although price-matching guarantees would then not be profitable) if the chain-store's price is moderately higher; and no guarantee is optimal if instead the chain-store's price is significantly higher.

\footnotetext{
${ }^{5}$ The use of low-price guarantees as a signaling device has been explored by Moorthy and Winter (2006).
} 
The intuition for these results is as follows. For any given item, the discrimination takes place around an anchor price, which is the price set by the rival chain store on that item. ${ }^{6}$ Consumers who buy from the small firm but who do not make use of its guarantee pay list price. We assume these consumers as a group are relatively less price sensitive. In contrast, consumers who buy from the small firm and who invoke its guarantee pay a price which is either at or below the anchor price, depending on whether the small firm has promised to match or beat its rivals' prices. These consumers tend to be relatively more price sensitive.

It follows that if the anchor price is very high, discrimination might not be profitable for the small firm because the distortion it would have to make to ensure that its list price was above the anchor price might result in a price that is too high for the group that does not make use of the guarantee. And, conversely, if the anchor price is very low, discrimination might not be profitable because the price paid by the consumers who do use the guarantee might then be too low relative to what the small firm would have liked to have charged them.

For intermediate cases, it is useful to compare the anchor price to the price the small firm would ideally like to charge if it could not discriminate. If the anchor price is only slightly higher or lower than the small firm's optimal uniform price, price-beating guarantees tend to do very well because they can be used to 'overcut'. To achieve overcutting, the firm optimally sets its list price at the level that maximizes its profit from its less price-sensitive consumers (which will be above the anchor price), and relies on the price-beating feature of its guarantee to lower its effective selling price to the level that maximizes its profit from its more price sensitive consumers (who are the ones who take advantage of the guarantee). If the anchor price is instead moderately higher or lower than the small firm's optimal uniform price, distortions relative to the two profit-maximizing group prices are inevitable. In these cases, a distortion at the higher end can best be mitigated when price-beating guarantees are used, whereas distortions at the lower end can best be mitigated when pricematching guarantees are used (indeed, they would be even worse if pricebeating guarantees were used).

Taken together, therefore, our analysis suggests that, when profitable, pricematching guarantees are likely to be more suitable for higher priced firms such as Eddie's Electronics, whereas price-beating guarantees are likely to be more suitable for lower priced firms such as Sam's Hardware (although there are some exceptions, for example, price-beating guarantees would be better for Eddie's Electronics when the chain-store's price is only slightly lower).

Before proceeding to review the literature, it is worth noting that the use of low-price guarantees to discriminate among consumers has been criticized

\footnotetext{
${ }^{6}$ We implicitly assume that if the small firm competes against more than one chain store, the chain stores all set the same price on the relevant item. This simplifies the exposition but is not essential for our results.
} 
because of a perception that too few customers would make use of the guarantees. However, there is some indication that usage rates-whatever they were in the past-may be changing with the emergence of the web as a way for consumers who are so inclined to gather competitor price information at relatively low cost, and at the same time, with a click of a button and a printer, to provide the necessary proof of a rival's lower price at the point of sale. Although we are unaware of systematic evidence of this, we offer two recent examples from the UK which suggest that, at least in some cases, usage by consumers has been substantial. Our first example is that of John Lewis, a department store in the UK, which has a long-standing policy of boasting that they are "never knowingly undersold". Citing the costs of matching competitor's prices on the web as being prohibitive, John Lewis recently restricted its price guarantee to apply only to rivals with brick-and-mortar shops. Our second example is that of the leading UK retailer, Tesco, which had to abandon its double the difference price-beating guarantee after just two months due to the large number of unanticipated redemptions by consumers. Although these examples are of policies that involve large firms and ultimately failed, they do suggest that a surprising number of consumers may take advantage of these guarantees when offered.

\subsection{Related literature}

Previous theoretical studies suggest that low-price guarantees may facilitate implicit price collusion. The idea is that by promising to match or beat any lower price announced by its rivals, a firm can reduce its rivals' incentives to cut prices in the first place. ${ }^{7}$ Although there is empirical evidence to suggest that this story may hold at least for some markets, ${ }^{8}$ it seems less plausible for the kinds of markets we are considering. We have thus ruled it out a priori by assuming that the chain-store's price is independent of the prices set by the small firm.

It has also been suggested that low-price guarantees may be used to signal low prices to consumers (see, for example, Jain and Srivastava 2000; Moorthy and Winter 2006). The idea is that high-priced firms would find it too costly to mimic a low-priced firm's strategy of offering low-price guarantees because too many consumers would request refunds. Although there is evidence consistent with this story as well, casual observation suggests that, for the markets we consider, firms with low-price guarantees do not always have the lowest prices.

\footnotetext{
${ }^{7}$ See, for example, the seminal papers by Hay (1982) and Salop (1986), and the early contributions by Baye and Kovenock (1994), Zhang (1995), Edlin and Emch (1999) and Hviid and Shaffer (1999). More recently, Coughlan and Shaffer (2009) consider the effect of these guarantees on firms' product-line choices.

${ }^{8}$ See the evidence presented in Hess and Gerstner (1991) and Arbatskaya et al. (1999, 2006).
} 
This leaves price discrimination as a possible motive. To our knowledge, the literature on the use of low-price guarantees to discriminate among consumers consists of four papers: Png and Hirshleifer (1987), Corts (1997), Chen et al. (2001a) and Nalca et al. (2010). ${ }^{9}$ Like us, these authors assume that some consumers are willing to use the guarantees, while others are not. In Png and Hirschleifer, "tourists" never shop around, while "locals" always take advantage of the best deal. They find that price-matching guarantees are always profitable, and both groups always end up paying higher prices. They do not consider price-beating guarantees. Corts distinguishes between sophisticated and unsophisticated customers and finds that prices to the sophisticated customers are always at marginal cost as a result of the firms' price-beating guarantees. In his model, price-matching guarantees are never observed when both price-matching and price-beating guarantees are feasible, and price-beating guarantees are always observed over uniform pricing. Chen et al. (2001a) are the first to show that price-matching guarantees need not be more profitable than uniform pricing. The reason is that, in their model, price-matching guarantees can increase competition for some consumers for some parameter values. They do not consider price-beating guarantees. Nalca et al. consider whether firms might want to discriminate not just on whether consumers are informed or uninformed, but also on whether the product is available at the rival store. Like Png and Hirschleifer and Chen et al., they do not consider price-beating guarantees.

Our results differ from the results in these papers in part because we are able to separate out the effects of pure price discrimination from the effects of competition. In those models, price discrimination occurs because one firm happens to have a lower list price than the other firm, with competition determining the level. In our model, price discrimination occurs because the small firm is able to use the chain-store's price as an anchor in sorting among consumers. But because the chain-store's price is unaffected by the local firm's prices, the low-price guarantees do not simultaneously play a role in affecting competition. As a result, we are able to explain why a small firm might sometimes find price-matching to be optimal, sometimes find price-beating to be optimal, and sometimes find no guarantee to be optimal.

Our analysis also relates to the vast literature on third-degree price discrimination. Most of this literature, however, restricts attention to a monopolist seller, and none to our knowledge considers the impact of anchoring. ${ }^{10}$ Taking anchoring into account yields new results. In the traditional price discrimination literature, the optimal uniform price is bounded above by the optimal group price for the less price-sensitive group and below by the optimal group

\footnotetext{
${ }^{9}$ Edlin (1990) discusses discriminatory motives for the use of low-price guarantees. However, the symmetry of his model permits no price dispersion in equilibrium, and hence there is no actual price discrimination.

${ }^{10}$ See Tirole (1988) and the chapters by Varian (1989) and Stole (2007) for surveys of this literature.
} 
price for the more price-sensitive group. However, with anchoring, it is not uncommon for the prices in both groups to be weakly higher (or weakly lower) than what they would have been under traditional third-degree price discrimination, and in some instances, it is even possible for the prices in both groups to be weakly higher than the optimal uniform price.

Non-traditional results have also been found in the more specialized literature on behavior-based price discrimination, where firms target discounts to their own customers as well as to their rival's customers, and where the strong and the weak markets are endogenously determined. ${ }^{11}$ This literature tends to find that prices to both groups will fall relative to the non-discriminatory uniform prices, whereas in our case, the opposite may be true-the prices to both groups may be weakly higher. Moreover, in our case, targeting individual consumers is not feasible, and the market segmentation occurs along more traditional lines.

The paper is organized as follows. Section 2 introduces the model. Section 3 considers the effects of price-matching guarantees. Section 4 considers the effects of price-beating gaurantees. Section 5 extends the model to consider welfare effects, and Section 6 concludes.

\section{Model}

We focus on the managerial decisions of a small, locally operated firm, which competes against one or more nationally operated chain stores in selling a branded product. The firms' products are imperfect substitutes in the sense that, at equal prices, some consumers will prefer buying from the local firm while others will prefer buying from the chain stores. ${ }^{12}$

The local firm faces a downward-sloping demand curve that is decreasing in its own price, $P$, and increasing in the common price of its rivals, $P_{x}$. We assume throughout our analysis that $P_{x}$ is exogenous in the sense that it is unaffected by the local firm's pricing decisions. ${ }^{13}$

We further assume that consumers differ in their willingness to invoke the price guarantees. Some consumers, which we denote as group A consumers, never use price guarantees. These consumers always buy at list prices. In

\footnotetext{
${ }^{11}$ See Corts (1998) for a discussion of strong and weak markets. For other early contributions to this literature, see Shaffer and Zhang (1995, 2002), Chen (1997), Chen et al. (2001b) and Chen and Iyer (2002).

${ }^{12}$ For example, some consumers may prefer the personalized attention they receive from the smaller store, while others may place more value on the convenience of buying from a store that is located closer to home.

${ }^{13}$ This assumption is justified, for example, if the chain-stores' prices are determined at the national level and implemented uniformly across local markets, which is the case for many markets in the United Kingdom (Dobson and Waterson 2005). Alternatively, one can think of the analysis in the paper as characterizing the small firm's "reaction function" to the chain stores' prices. One can then endogenously implement the various regimes identified in Tables 2 and 3 by varying up or down the marginal costs of the chain stores.
} 
contrast, the remaining consumers, which we denote as group B consumers, use price guarantees whenever possible. ${ }^{14}$ These consumers are assumed to be on average more price sensitive than the consumers in group A.

Let $c$ denote the local firm's marginal cost. Let $D_{i}\left(P ; P_{x}\right)$ denote its demand from group $i$ consumers, $i=A, B$. Then, the firm's maximized profit under uniform pricing is given by

$$
\Pi^{U}\left(P_{x}\right) \equiv\left(P_{U}-c\right) D_{A}\left(P_{U} ; P_{x}\right)+\left(P_{U}-c\right) D_{B}\left(P_{U} ; P_{x}\right)
$$

where the first term is the profit it receives from group A consumers, the second term is the profit it receives from group $\mathrm{B}$ consumers, and $P_{U}$ is the profit-maximizing uniform price:

$$
P_{U}\left(P_{x}\right) \equiv \arg \max _{P}(P-c) D_{A}\left(P ; P_{x}\right)+(P-c) D_{B}\left(P ; P_{x}\right) .
$$

This price, which is the inverse of the firm's average elasticity of demand across the two groups, is a compromise between the price that would maximize its profit from the (less elastic) group A consumers and the price that would maximize its profit from the (more elastic) group B consumers. It follows that since the group B consumers are more elastic,

$$
P_{B}\left(P_{x}\right)<P_{U}\left(P_{x}\right)<P_{A}\left(P_{x}\right),
$$

where $P_{i}\left(P_{x}\right)$ is the price that maximizes the firm's profit from the group $i$ consumers,

$$
P_{i}\left(P_{x}\right) \equiv \arg \max _{P}(P-c) D_{i}\left(P ; P_{x}\right) \quad i=A, B .
$$

If the local firm could directly engage in price discrimination between the two groups, it would want to charge $P_{A}\left(P_{x}\right)$ to group A consumers and $P_{B}\left(P_{x}\right)$ to group $\mathrm{B}$ consumers. However, when the discrimination can only occur indirectly, through the use of low-price guarantees, then, as we shall see, whether or not the local firm can reach these ideals will depend on both the form of the guarantee it chooses and the anchor price of the chain store.

We assume for convenience that profit functions are concave, so that the local firm's profit-maximizing prices can be found from first-order conditions. We also assume that whereas the chain store's price does not depend on the price set by the local firm (for the reasons we have indicated), the local firm's prices will in general be sensitive to the prices charged by the chain store. In particular, we assume that the local firm's profit-maximizing prices are greater

\footnotetext{
${ }^{14}$ These behavioral types are caricatures of the kinds of consumers the local firm might be expected to find in practice. Group A consumers, for example, may not be aware of the firm's low-price guarantee, or they may think that any potential savings are outweighed by the inconvenience/hassle costs of asking for a refund. In contrast, group B consumers always seek out the best deal, even if it means incurring extra hassle. When buying from the local firm, these consumers prefer to purchase at the lowest possible price.
} 
than $c$ (which implies that the firm has some market power), and that these prices are increasing in $P_{x}$ (which implies that reaction functions are upward sloping, as they will be, for example, if demands are linear). We further assume that own effects dominate cross effects in demand, so that the slope of $P_{i}\left(P_{x}\right)$, $i=A, B, U$, is less than unity.

These assumptions ensure that if $P_{x}$ is low enough, the local firm would want to set $P_{A}>P_{x}$ and $P_{B}>P_{x}$, whereas if $P_{x}$ is high enough, the local firm would want to set $P_{A}<P_{x}$ and $P_{B}<P_{x}$. For intermediate values of $P_{x}$, the local firm would want to set $P_{A}>P_{x}$ to group A consumers (if it could) and $P_{B}<P_{x}$ to group B consumers (if it could).

\section{Price-matching guarantees}

A price-matching guarantee is a promise to match any lower price offered by a competitor on an identical item. This means that if the local firm announces a list price of $P>P_{x}$ and offers a price-matching guarantee, then any consumer who takes advantage of the offer will be able to buy at the price $P_{x}$, whereas any consumer who does not take advantage of the offer will pay $P$. Since only group B consumers use the guarantee, it follows that the local firm's maximization problem when it announces $P$ and offers to match prices is given by

$$
\max _{P}(P-c) D_{A}\left(P ; P_{x}\right)+\left(\min \left\{P, P_{x}\right\}-c\right) D_{B}\left(\min \left\{P, P_{x}\right\} ; P_{x}\right) .
$$

It should be clear from Eq. 3 that if there is to be an effect from offering a price-matching guarantee, it must be because groups $\mathrm{A}$ and $\mathrm{B}$ pay different prices, and thus, the local firm's maximization problem in any setting in which price matching is optimal can be rewritten as

$$
\max _{P \geq P_{x}}(P-c) D_{A}\left(P ; P_{x}\right)+\left(P_{x}-c\right) D_{B}\left(P_{x} ; P_{x}\right) .
$$

Since the chain-store's price is exogenous, the profit that comes from the second term in Eq. 4 is also exogenous, which means that the local firm will choose $P$ to maximize its profit from the group A consumers as long as $P_{x}$ is not too high (i.e., as long as $P_{x}<P_{A}\left(P_{x}\right)$ ). Otherwise, the constraint in Eq. 4 is binding and the firm is better served with no guarantee.

Assuming therefore that the chain-store's price is less than the optimal price to group A consumers, $P_{x}<P_{A}\left(P_{x}\right)$, the local firm obtains a maximized profit under price matching of

$$
\Pi^{P M}\left(P_{x}\right) \equiv\left(P_{A}-c\right) D_{A}\left(P_{A} ; P_{x}\right)+\left(P_{x}-c\right) D_{B}\left(P_{x} ; P_{x}\right) .
$$

Table 1 below provides a group-by-group comparison of the local firm's profits in Eqs. 1 and 5. Since price-matching allows the local firm to charge 
Table 1 Contribution to total profits from each group

\begin{tabular}{lll}
\hline Total profit & Group A & Group B \\
\hline$\Pi^{P M}\left(P_{x}\right)$ & $\left(P_{A}-c\right) D_{A}\left(P_{A} ; P_{x}\right)$ & $\left(P_{x}-c\right) D_{B}\left(P_{x} ; P_{x}\right)$ \\
$\Pi^{U}\left(P_{x}\right)$ & $\left(P_{U}-c\right) D_{A}\left(P_{U} ; P_{x}\right)$ & $\left(P_{U}-c\right) D_{B}\left(P_{U} ; P_{x}\right)$ \\
\hline
\end{tabular}

its optimal price to group A consumers, whereas it cannot do so in the absence of price matching, it should be clear that the firm earns higher profit from group A consumers when it offers price matching than when it does not. The situation with respect to group B consumers, however, is more complicated. Although it is possible that the firm will also earn higher profit from group B consumers when it offers price-matching (this would be the case, for example, if the chain store's price was equal to $P_{B}$ ), this need not be the case. For some values of $P_{x}$, it would incur a loss. The loss from the group B consumers may even outweigh the gain from the group A consumers.

In the Appendix, we characterize the domain of anchor prices $P_{x}$ for which the net gain from group A consumers outweighs any net loss from group B consumers, $\Pi^{P M}\left(P_{x}\right) \geq \Pi^{U}\left(P_{x}\right)$. We also demonstrate the existence of a lower bound on $P_{x}, P_{L}^{P M}$, which is less than $P_{B}$, and an upper bound on $P_{x}, P_{H}^{P M}$, which is between $P_{U}$ and $P_{A}$, such that for all values of $P_{x}$ between $P_{L}^{P M}$ and $P_{H}^{P M}$, the local firm's profit under price matching will be higher than that under uniform pricing. For all values of $P_{x}$ which are outside of these bounds, we show that the local firm's profit will be lower under price matching (than under uniform pricing). Thus, our analysis yields five intervals with distinct implications for prices and guarantees:

\subsection{Implications for Eddie's Electronics and Sam's Hardware}

Table 2 has implications for the two cases presented in the Introduction. We highlight these implications first for the case of Eddie's Electronics and then for the case of Sam's Hardware.

Eddie's Electronics Recall that Eddie's prices are higher than those of its chain-store competitors in the absence of price matching, which implies that

Table 2 Effect of different chain-store prices

\begin{tabular}{llll}
\hline Range & $\begin{array}{l}\text { Price in } \\
\text { market } A\end{array}$ & $\begin{array}{l}\text { Price in } \\
\text { market } B\end{array}$ & Guarantee \\
\hline$P_{x}<P_{L}^{P M}$ & $P_{U}$ & $P_{U}$ & None \\
$P_{x} \in\left[P_{L}^{P M}, P_{B}\right]$ & $P_{A}$ & $P_{x}$ & PM \\
$P_{x} \in\left(P_{B}, P_{U}\right)$ & $P_{A}$ & $P_{x}$ & PM \\
$P_{x} \in\left[P_{U}, P_{H}^{P M}\right]$ & $P_{A}$ & $P_{x}$ & PM \\
$P_{x}>P_{H}^{P M}$ & $P_{U}$ & $P_{U}$ & None \\
\hline
\end{tabular}


$P_{x}<P_{U}$. Thus, the case of Eddie's Electronics corresponds to the first three rows of Table 2 . This yields the following managerial implications:

- If the chain-store's price is only slightly less than Eddie's optimal uniform price, $P_{x} \in\left(P_{B}, P_{U}\right)$, Eddie's should offer to match prices and raise its list price to $P_{A}$ in order to optimally serve its group A consumers. Group B consumers who buy from Eddie's will use Eddie's guarantee to lower their effective purchasing price to $P_{x}$. Notice that group A consumers will be no worse off than if they were discriminated against directly, but group B consumers will be worse off than if they were discriminated against directly.

- Eddie's optimal strategy is the same if the chain-store's price is moderately less than Eddie's optimal uniform price, $P_{x} \in\left[P_{L}^{P M}, P_{B}\right]$, but in this case group B consumers will actually be better off (not worse off) than if they were discriminated against directly.

- If the chain-store's price is significantly less than Eddie's optimal uniform price, $P_{x}<P_{L}^{P M}$, Eddie's should not offer a price-matching guarantee and continue to charge $P_{U}$.

Anchoring on the chain-store's price implies that group A consumers will lose from Eddie's policy, whereas group B consumers will gain from it, when price-matching is offered.

Sam's Hardware The case of Sam's Hardware corresponds to the fourth and fifth rows of Table 2, which follows because Sam's prices are lower than those of its chain-store competitors in the absence of price matching. We thus have the following managerial implications for Sam's Hardware:

- If the chain-store's price is only slightly higher than Sam's optimal uniform price, $P_{x} \in\left[P_{U}, P_{H}^{P M}\right]$, Sam's should offer a price-matching guarantee and raise its list price to $P_{A}$ in order to optimally serve its group A consumers. Group B consumers who buy from Sam's will use Sam's guarantee to lower their effective purchasing price to $P_{x}$.

- If the chain-store's price is moderately higher (or significantly higher) than Sam's optimal uniform price, $P_{x}>P_{H}^{P M}$, Sam's should not offer a pricematching guarantee.

Anchoring on the chain-store's price implies that group B consumers will not only be worse off than if Sam's had discriminated against them directly $\left(P_{x}>P_{B}\right)$, they will also be worse off period $\left(P_{x}>P_{U}\right)$. And since Sam's list price increases, group A consumers will also be worse off. It follows that all consumers will lose from Sam's policy of price-matching.

\subsection{Summary}

These observations suggest that discrimination that occurs via anchoring on the chain-store's price yields results that are qualitatively different from what one would get with direct price discrimination, and collectively they 
demonstrate that neither price-matching guarantees nor uniform pricing will always be preferred. We formally summarize these results as follows.

Proposition 1 The local firm earns strictly higher profit under price matching than under uniform pricing if and only if the chain-store's price is such that $P_{L}^{P M}<P_{x}<P_{H}^{P M}$.

Intuitively, the local firm would like to discriminate between its consumers by setting a high list price for its group A consumers and taking advantage, through its offer to match, of lower list prices elsewhere to charge a lower price to its group B consumers. The problem is that the lower list prices elsewhere need not have any relation to the optimal price the local firm would like to charge its group B consumers. Thus, anchoring on these list prices may not be profitable, and even if it is profitable, group B consumers may or may not gain.

Several implications follow from Proposition 1. First, as we have already explained, price-matching guarantees are not always optimal. Although this implication accords with what one observes in reality (i.e., not all firms choose to have price-matching guarantees), it contrasts with the findings of many, if not most, models of price-matching guarantees, which are set up to explain why firms might want to match prices but not why they would not. ${ }^{15}$ In contrast, our analysis suggests that whether or not price matching will be more profitable than uniform pricing for the local firm depends on the prices charged by the chain store.

Second, we find that the difference in the local firm's profit in the two cases is not monotonic. Price matching is more profitable than uniform pricing for intermediate values of $P_{x}$ but less profitable than uniform pricing when the anchor price is very low or very high.

Third, we find that price matching via anchoring is an imperfect substitute for direct price discrimination. If the local firm could directly charge different prices, it would want to charge $P_{A}$ to group A consumers and $P_{B}$ to group B consumers. With price matching, the firm does indeed charge $P_{A}$ to the group A consumers, but unfortunately for the local firm, group B consumers will only be able to purchase at $P_{x}$, which need not be equal to $P_{B}$.

To further emphasize that price matching via anchoring is an imperfect substitute for direct price discrimination, recall that in the latter case, prices generally rise to some consumer groups and fall to others. In contrast, as illustrated in Fig. 1, for all $P_{x}$ such that $P_{U}<P_{x}<P_{H}^{P M}$, price matching will be optimal and there will be a price increase, not only for group A consumers, but also for group B consumers (i.e., prices to both groups will rise).

Finally, note that this implication of overall higher prices is also predicted by other models in the literature on low-price guarantees, but usually in the

\footnotetext{
${ }^{15}$ Many models in the literature on price guarantees over explain the phenomenon they attempt to describe (e.g., the model may predict that price matching emerges as the unique outcome for all parameter values).
} 
Fig. 1 Optimal price matching

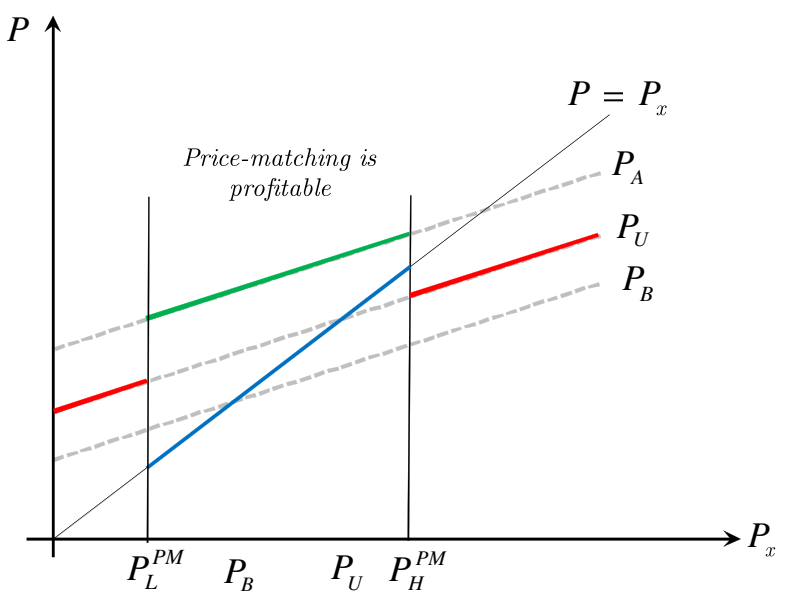

context of dampening competition. We have abstracted from this by assuming the chain-store's price is exogenous.

\section{Price-beating guarantees}

We now expand the strategy space to include guarantees in which a firm offers to beat any lower price announced by a competitor by some percentage $\lambda$ of the difference. ${ }^{16}$ Thus, if the local firm offers a price-beating guarantee and chooses a list price of $P>P_{x}$, then any consumer who does not take advantage of the guarantee pays $P$, whereas any consumer who does takes advantage of the guarantee pays $P-(1+\lambda)\left(P-P_{x}\right)$, or equivalently, $P_{x}-\lambda \cdot\left(P-P_{x}\right)$. For example, an offer to beat any lower price by $25 \%$ of the difference corresponds to a $\lambda=.25$, while an offer to "double the difference" corresponds to $\mathrm{a} \lambda=1$.

In practice, one might expect there to be an upper bound on the maximum price-beating percentage a local firm will consider. Among other things, this upper bound might depend on the kinds of products being sold, the local firm's tolerance for risk, and consumers' perceptions of the believability of the firm's guarantee. ${ }^{17}$ Let $\bar{\lambda}$ denote this upper bound. It follows that since group B

\footnotetext{
${ }^{16}$ This form accounts for approximately $86 \%$ of all price-beating guarantees in Arbatskaya (2004) et al.'s dataset. We refer the reader to their study for other descriptive statistics on price-beating guarantees.

${ }^{17}$ See, for example, Kukar-Kinney and Walters (2003), who test consumer attitudes of price beating guarantees using experimental survey methods. They find that a modest price beating guarantee is perceived as being less believable but also as having a greater value to the consumer than a price matching guarantee. Desmet and Le Negard (2005) confirm this finding using a price beating guarantee of 10 times the difference. Interestingly, the credibility of the guarantee does not collapse with this extreme price beating percentage.
} 
consumers take advantage of guarantees, whereas group A consumers do not, the firm's maximization problem when it offers a guarantee is given by

$$
\max _{P, 0 \leq \lambda \leq \bar{\lambda}}(P-c) D_{A}\left(P ; P_{x}\right)+(S-c) D_{B}\left(S ; P_{x}\right),
$$

where

$$
S=P-(1+\lambda) \cdot \max \left\{P-P_{x}, 0\right\}
$$

is the price at which group B consumers can buy from the local firm. Note that price-matching is a special case of price beating. We say that price-matching is optimal if the local firm prefers to set $\lambda=0$, price-beating is optimal if it prefers to set $\lambda>0$, and no guarantee is optimal if Eq. 6 yields weakly lower profit for the firm than it would earn under simple uniform pricing.

We will proceed with three observations. Each observation contrasts with existing literature.

Observation 1 Previous literature suggests that when both price-matching and price-beating guarantees are feasible, price-beating will always be chosen over price-matching. This is the case, for example, in Corts $(1995,1997)$ and Hviid and Shaffer (1994). However, it is not true in our setting. If the price set by the chain store is less than or equal to the profit-maximizing price for group $\mathrm{B}$ consumers, $P_{x} \leq P_{B}$, then a strategy of charging a list price above $P_{x}$ and offering a price-beating guarantee only makes things worse for the firm (because it reduces the profits from the group B consumers even further). ${ }^{18}$ In this case, charging the same list price but offering only to match prices would yield strictly higher profit. It follows that price-matching guarantees will be preferred over price-beating guarantees for all $P_{x} \leq P_{B}$.

Observation 2 Previous literature also suggests that price-beating guarantees, when observed, lead to marginal-cost pricing and low profits (because they intensify competition and result in a prisoner's dilemma situation). In contrast, in our setting, when $P_{B}<P_{x}<P_{A}$, price-beating guarantees can be extremely profitable. To illustrate this, consider the following simple example. Suppose group A's profit-maximizing price is 100, group B's profit-maximizing price is 80 , and the chain-store's price is 85 . Then, the local firm can maximize its profit by choosing a list price of $P=100$ and offering to beat any lower price by $\lambda=.33$. With this strategy, consumers in group A (who do not use the guarantee) pay the list price of 100 while consumers in group B (who take advantage of the guarantee) pay only $85-.33 \cdot(100-85)=80$. As a result, all consumers face the firm's profit-maximizing price for their respective group.

${ }^{18}$ This observation relies only on the assumed concavity of the group B consumers' profit function. 
More generally, two elements are essential for the firm to realize its "first best profit": $P_{x}$ must lie between the profit-maximizing prices of the two groups, and the requisite price-beating percentage must be feasible (.33 in our example above). ${ }^{19}$ When these two elements are in place, the firm maximizes its profit by setting a list price of $P_{A}$ (this maximizes its profit from the group A consumers) and a price-beating percentage such that, given its list price and the chain-store's price, its effective selling price to the group B consumers becomes $P_{B}$ after its guarantee is invoked (this maximizes its profit from the group B consumers). ${ }^{20}$ This strategy dominates what the firm could earn under price-matching, and it dominates what the firm could earn from simple uniform pricing. In fact, it does so well that it allows the firm to earn the same profit that would be earned if direct price discrimination were feasible.

Observation 3 Even when the firm's first best profit cannot be realized, either because the price-beating percentage that would be required to obtain the first best exceeds what the firm is willing to consider, or because the chain-store's price exceeds $P_{A}$, it is still the case that price-beating guarantees will yield higher profit than price-matching guarantees over a wide range of parameters. Consider, for example, the region in which $P_{B}<P_{x} \leq P_{H}^{P M}$ (recall that $P_{H}^{P M}$ is the price at which the local firm is indifferent between a price-matching guarantee and uniform pricing). Then, as we showed previously, the local firm's profit under price matching is given by

$$
\left(P_{A}-c\right) D_{A}\left(P_{A} ; P_{x}\right)+\left(P_{x}-c\right) D_{B}\left(P_{x} ; P_{x}\right) \text {. }
$$

With price-beating guarantees, the local firm can do better. It can choose the same list price as in price-matching, $P=P_{A}$, but by offering to beat the chain-store's price by some arbitrarily small percentage of the difference, it can ensure that group B consumers will be able to purchase at some price $P_{x}^{-}$, which is close to but strictly lower than $P_{x}$. This yields

$$
\left(P_{A}-c\right) D_{A}\left(P_{A} ; P_{x}\right)+\left(P_{x}^{-}-c\right) D_{B}\left(P_{x}^{-} ; P_{x}\right) .
$$

Comparing Eqs. 7 and 8, it follows that the profit from the group A consumers is the same in both cases, while the profit from the group B consumers is higher in Eq. 8. This conclusion relies only on the concavity of the group B consumers'

\footnotetext{
${ }^{19} \mathrm{~A}$ wide range of price-beating percentages are observed in practice. Of the 163 price-beating guarantees in Arbatskaya et al.'s (2004) data, price-beating percentages varied from a low of $10 \%$ to a high of $310 \%$. (Desmet and Le Negard 2005, 293) report that the Supermarket chain Carrefour has had a price guarantee promising to refund ten times the difference.

${ }^{20}$ We call this strategy "overcutting". Instead of lowering the price to group B consumers by charging a list price below $P_{x}$ (which would also give the lower price to group A consumers), the firm lowers the price to group B consumers by raising its list price and then offering to beat the competitor's lower price.
} 
Table 3 Effect of different chain-store prices

\begin{tabular}{llll}
\hline Range & $\begin{array}{l}\text { Price in } \\
\text { market } A\end{array}$ & $\begin{array}{l}\text { Price in } \\
\text { market } B\end{array}$ & Guarantee \\
\hline$P_{x}<P_{L}^{P M}$ & $P_{U}$ & $P_{U}$ & None \\
$P_{x} \in\left[P_{L}^{P M}, P_{B}\right]$ & $P_{A}$ & $P_{x}$ & PM \\
$P_{x} \in\left(P_{B}, P_{U}\right)$ & $P_{A}^{+}$ & {$\left[P_{B}, P_{x}\right)$} & PB \\
$P_{x} \in\left[P_{U}, P_{H}^{P B}\right]$ & $P_{A}^{+}$ & {$\left[P_{B}, P_{x}\right)$} & PB \\
$P_{x}>P_{H}^{P B}$ & $P_{U}$ & $P_{U}$ & None \\
\hline
\end{tabular}

profit function (as the selling price moves closer to $P_{B}$, one is moving to a position of higher profits from group B consumers).

Moreover, it follows from the continuity of the profit functions that pricebeating guarantees will continue to do better for the local firm even for $P_{x}$ above $P_{H}^{P M}$, over some range. The extent of this range will depend on the set of feasible $\lambda$. With no restrictions, on $\lambda$, for example, we know that this range will include $P_{x}=P_{A}$ because for all $P_{x}$ greater than $P_{B}$ and less than or equal to $P_{A}$, the local firm can obtain the first best, as we have discussed, by choosing a list price of $P=P_{A}$ and setting $\lambda$ such that the group B consumers pay $P_{B}$.

Let $P_{H}^{P B}$ denote the upper bound on the range of $P_{x}$ such that price-beating guarantees are profitable. Then, for $P_{B}<P_{x} \leq P_{H}^{P B}$, we would expect to observe the local firm offering a price-beating guarantee, while for $P_{x}>P_{H}^{P B}$, we would expect no guarantee to be offered.

Implications for prices and guarantees Our analysis thus yields five intervals with distinct implications for prices and guarantees, see Table 3 .

The notation $P_{A}^{+}$denotes a scenario in which the local firm charges a list price which is weakly higher than $P_{A}$, and the notation $\left[P_{B}, P_{x}\right)$ denotes a scenario in which the effective price to group B consumers is bounded below by $P_{B}$ (inclusive of $P_{B}$ ), and above by $P_{x}$. The reason for the different scenarios in the case of price beating is due to the local firm's choice of $\lambda$ possibly being restricted in practice. In the absence of a restriction on $\lambda$, for example, the price to group $\mathrm{B}$ consumers will always be $P_{B}$ when the local firm adopts price beating, and the price to group A consumers will be $P_{A}$, unless $P_{x}>P_{A}$, in which case the price to group A consumers will necessarily exceed $P_{A}$. When the set of feasible $\lambda$ is restricted and binding, the price to the group A consumers will generally be distorted upward (greater than $P_{A}$ ) in order to induce the effective price to the group B consumers to be closer to $P_{B}$.

\subsection{Implications for Eddie's Electronics and Sam's Hardware}

We now present the implications of our analysis for Eddie's and Sam's. 
Eddie's Electronics When both price-matching and price-beating guarantees are feasible:

- If the chain-store's price is only slightly less than Eddie's optimal uniform price, $P_{x} \in\left(P_{B}, P_{U}\right)$, Eddie's should adopt a price-beating guarantee and raise its list price to $P_{A}^{+}$. Group B consumers who buy from Eddie's will then use Eddie's guarantee to lower their effective purchasing price to below $P_{x}$. Notice that it is possible for both groups of consumers to be strictly worse off than if they were discriminated against directly.

- If the chain-store's price is moderately or significantly less than Eddie's optimal uniform price, then Eddie's optimal strategy is the same as before. In the former case, $P_{x} \in\left[P_{L}^{P M}, P_{B}\right]$, Eddie's should raise its list price to $P_{A}$ and adopt a price-matching policy. In the latter case, $P_{x}<P_{L}^{P M}$, Eddie's should not offer a guarantee and charge $P=P_{U}$.

Anchoring on the chain-store's price implies that group A consumers will lose from Eddie's policy, while group B consumers will gain from it, when lowprice guarantees are offered.

Sam's Hardware When both price-matching and price-beating guarantees are feasible:

- If the chain-store's price is slightly to moderately higher than Sam's optimal uniform price, $P_{x} \in\left[P_{U}, P_{H}^{P B}\right]$, Sam's should offer a price-beating guarantee and raise its list price to $P_{A}$ if the first best is feasible, or above $P_{A}$ if the first-best is not feasible. Group B consumers who buy from Sam's will then use Sam's guarantee to lower their effective purchasing price to below $P_{x}$, and possibly to $P_{B}$ if the first-best is feasible.

- If the chain-store's price is significantly higher than Sam's optimal uniform price, $P_{x}>P_{H}^{P B}$, Sam's should not offer a low-price guarantee and continue to charge $P=P_{U}$.

Anchoring on the chain-store's price implies that both consumer groups may be worse off (and will never be better off) than if Sam's had discriminated against them directly. Consumers in group A will always lose from Sam's policy, while consumers in group B may or may not gain, depending on whether their effective price does or does not fall below $P_{U}$.

\subsection{Summary}

We have now fully characterized when price beating does best, when price matching does best, and when no price guarantee does best. Our results can be summarized as follows.

Proposition 2 The local firm earns strictly higher profit under price beating than under the alternatives if and only if $P_{B}<P_{x}<P_{H}^{P B}$. It earns strictly higher profit under price matching than under the alternatives if and only if $P_{L}^{P M}<$ 
$P_{x}<P_{B}$. It earns strictly higher profit under uniform pricing than under the alternatives if and only $P_{x}<P_{L}^{P M}$ or $P_{x}>P_{H}^{P B}$.

Proposition 2 and the proceeding discussion implies that prices to both groups of consumers will be higher when price-beating guarantees are observed than when price-matching guarantees are observed, as illustrated in Fig. 2. In this case, the prices to the group $\mathrm{A}$ and $\mathrm{B}$ consumers are $P_{A}\left(P_{x}\right)$ and $P_{x}$, respectively, under price matching, $P_{A}\left(P_{x}\right)$ and $P_{B}\left(P_{x}\right)$, respectively, under price beating when $\lambda<\bar{\lambda}$, and strictly greater than $P_{A}\left(P_{x}\right)$ and strictly greater than $P_{B}\left(P_{x}\right)$, respectively, under price beating when $\lambda=\bar{\lambda}$. The claim follows trivially by noting that $P_{A}\left(P_{x}\right)$ is increasing in $P_{x}$, and $P_{x}<P_{B}\left(P_{x}\right)$ under price matching. Note that relative to uniform pricing, however, the price to group A consumers always increases, and the price to group B consumers always decreases, when low-price guarantees are offered.

It also follows from Proposition 2 that there are two senses in which pricebeating guarantees can do better than price-matching guarantees. First, pricebeating guarantees can mimic direct price discrimination for all $P_{x}$ such that $P_{B}<P_{x}<P_{A}$, provided that $\lambda$ is not binding. In contrast, price-matching guarantees can mimic direct price discrimination only when $P_{x}=P_{B}$. Second, price-beating guarantees can increase the local firm's profit relative to uniform pricing when $P_{x}$ is in the region $P_{H}^{P M}<P_{x}<P_{H}^{P B}$, whereas price-matching guarantees cannot. However, it also follows that price beating can sometimes do worse than price matching. For example, price matching does better if $P_{L}^{P M}<P_{x}<P_{B}$. The reason is that in this case the effective selling price to the group B consumers is already sufficiently low, and promising to beat a rival's already low price will only serve to exacerbate matters.

Finally, it follows that low-price guarantees are not always optimal. Indeed, for all $P_{x}<P_{L}^{P M}$ and $P_{x}>P_{H}^{P B}$, uniform pricing does strictly better than

Fig. 2 Optimal low-price guarantees

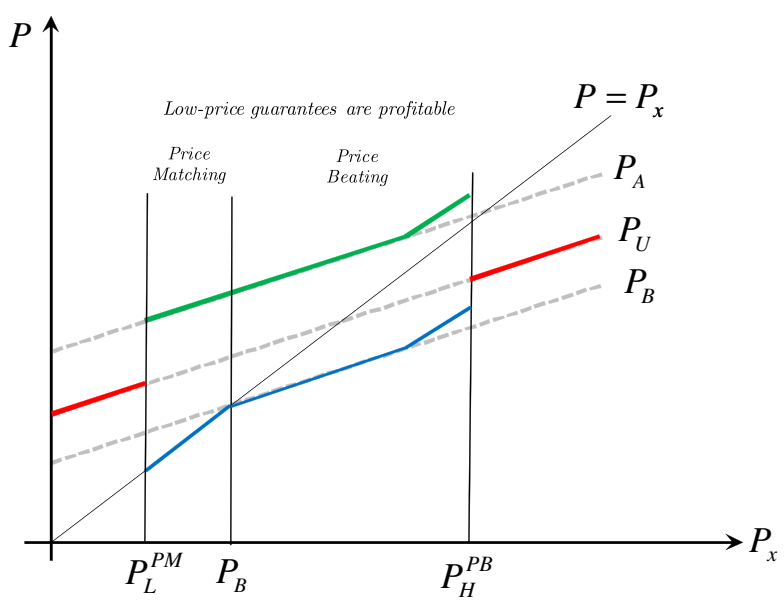


either price matching or price beating. The intuition is that the firm would not distort downward its effective price to the group B consumers if $P_{x}$ is too low, nor would it want to distort upward its list price to the group A consumers if $P_{x}$ is too high. An immediate implication of this is that low-price guarantees will be profitable only if the chain-store's price is in some intermediate range.

\section{A tale of two benchmarks}

We have been using uniform pricing as our benchmark, and asking the question, can the local firm do better by offering a low-price guarantee? To recap, the answer to the firm's question is "yes, sometimes." Rather than charge the same price to every consumer, the firm can potentially take advantage of different consumers' willingness' to pay by going after the group A consumers with its list price and free riding, as it were, on the chain-store's price by allowing its group B consumers to purchase at or below the price set by the chain store. As long as the chain-store's price is not too high or too low, this will be a profitable strategy.

Uniform pricing is clearly the relevant benchmark from the firm's perspective (which wants to know whether, and under what circumstances, it can increase its profit). And it is also the relevant benchmark from a public policy perspective if one wants to know who gains, who loses, and whether in aggregate consumers are likely to be better or worse off. In this regard, we have found that low-price guarantees always result in higher list prices, and thus harm consumers in group A-but whether consumers in group B gain or lose, however, depends on the relationship between the chain-store's price and the uniform price that would otherwise have been charged. As can be seen from Fig. 1, sometimes they gain and sometimes they lose. This latter finding is especially surprising because it suggests that there may be circumstances in which all consumers can be made worse off from the guarantees, not just those who are less price sensitive. However, it can also be seen that these circumstances do not arise when price beating guarantees are feasible (Fig. 2). In this case, the consumers in group B always benefit from the local firm's low-price guarantee.

It follows that a policy of banning price-beating guarantees, while allowing price-matching guarantees (i.e., moving from Figs. 2 to 1), for example, might unambiguously make things worse for consumers-hardly a good outcome for policy. More generally, however, a policy assessment of low-price guarantees likely involves a tradeoff; the guarantees make group A consumers worse off while making group B consumers and the firm better off. It then becomes an empirical question whether in aggregate society will be better or worse off.

And this is where a second benchmark comes into play. Short of actually estimating demand curves in any particular instance, and aggregating gains 
and losses in a brute force manner, there is a large body of literature which has looked at the welfare effects of direct price discrimination. Some of this literature is insightful. It suggests that one can usefully express the policy tradeoff in terms of a misallocation effect and an output effect. The former effect arises because, with discrimination, output is inefficiently distributed across markets. This negative feature of discriminatory pricing, however, may be offset if there is an increase in output sold to consumers, which is socially desirable because prices exceed marginal cost.

The key is to identify when the output effect will offset the misallocation effect. It was first shown by Robinson (1933), then by Schmalensee (1981), and most recently by Aguirre et al. (2010) that the curvature of demands is critical in determining the sign of the output effect. With linear demands, for example, it is known that if both markets are served at the uniform price, output will be unchanged under discrimination, and thus discrimination will be unambiguously bad. More generally, they have found that the more convex is the demand curve of the group B consumers relative to that of the group A consumers, the more likely the output effect will be positive, and thus the more likely price discrimination will be good.

While our intent is not to recreate their analyses, we can nevertheless usefully apply their insights to our model because of the following surprising feature of our analysis: in a setting in which both price-matching and pricebeating guarantees are feasible, if price matching (price beating) is observed, then the effective selling prices to the two groups of consumers will be weakly lower (higher) than they would have been under direct price discrimination. This follows immediately from Fig. 2 because in the case of price matching, which holds for the region $P_{L}^{P M}<P_{x}<P_{B}$, group A consumers pay $P_{A}$ and group B consumers pay less than $P_{B}$, whereas in the case of price beating, which holds for the region $P_{B}<P_{x}<P_{H}^{P B}$, group A consumers always pay at least $P_{A}$ and group $\mathrm{B}$ consumers always pay at least $P_{B}$.

It follows therefore that if one were to conclude that direct price discrimination would reduce welfare in a given instance, then one must also conclude that price-beating guarantees would reduce welfare in the same instance, whereas the latter might still lead to lower welfare even if direct price discrimination would not. Conversely, if one were to conclude that direct price discrimination would increase welfare in a given instance, then one must also conclude that price-matching guarantees would increase welfare in the same instance, whereas the latter might still lead to higher welfare even if direct price discrimination would not.

For a more thorough understanding of the theoretical conditions under which welfare can be expected to rise or fall under direct price discrimination by a monopolist, we refer the interested reader to Aguirre et al. (2010). In the abstract, however, and for the reasons just discussed, we see no reason for policy makers to condemn the use of low-price guarantees per se, and even less reason for policy makers to ban price-beating while allowing price-matching. 


\section{Conclusion}

Our objective in this paper was to explain why small, local firms might want to adopt low-price guarantees even if they would have no effect on their larger rivals' prices. ${ }^{21}$ The answer we hypothesized was that the firms might be using their guarantees to effectively discriminate between consumer groups with different price sensitivities (in other words, to price discriminate). However, different from existing theory, we offered a theory of price discrimination based on anchoring, which led to some unexpected qualitative insights (e.g., with price-matching guarantees, it is actually possible for both consumer groups to pay higher prices with low-price guarantees than without). It also meant that we could offer meaningful prescriptions as to when a firm should adopt a price-matching guarantee versus a price-beating guarantee, and when a firm would be better off offering no price guarantee.

The setting we focused on distinguishes our paper from much of the previous literature on low-price guarantees in which the effects of low-price guarantees are invariably wrapped up in their ability, more or less, to reduce rivals' incentives to cut prices. As a result, we are able to offer a more nuanced, and balanced policy perspective, in contrast to the calls of some authors to ban low-price guarantees. ${ }^{22}$ In our model, low-price guarantees might be procompetitive or anti-competitive, depending on the circumstance, and in this sense we echo the conclusion of Chen et al. (2001a) that low-price guarantees need not reduce welfare.

More importantly, we are the first, to our knowledge, to offer managerial guidance as to whether and when a firm should offer a low-price guarantee, and what form it should take. In contrast, many authors end up explaining too much in the sense that low-price guarantees are always profitable. Here, lowprice guarantees may or may not be profitable.

We are also the first, to our knowledge, to consider the effects of an upper bound on the maximum price-beating percentage a firm would consider, and to incorporate explicitly this constraint into the analysis. As it turns out, this constraint, if binding, matters from the consumers' perspective, because without any constraints, they would be always be paying lower prices. Thus, a firm that decides that offering a price beating guarantee in which it promises to beat any rival's lower price by $50 \%$ of the difference in price is the maximum it would be willing to consider, say because of concerns of too much exposure

\footnotetext{
${ }^{21}$ Our maintained assumption that the chain-stores' prices are independent of the local firm's prices is not as restrictive as it may seem. One can also think of the analysis here as characterizing the small firm's "reaction function" to the chain stores' prices. By varying up or down the marginal costs of the chain stores, one can then endogenously implement each of the regimes identified in Tables 2 and 3 .

${ }^{22}$ See the articles by Sargent (1993) and Edlin (1997), and discussion in the survey by Winter (2008).
} 
to risk if the rival should price lower than expected, might inadvertently be harming its own consumers.

A useful direction for future research might be to use our framework to explore other types of low-price guarantees observed in practice. One could then begin to map out a more comprehensive ranking of the different types. For example, Arbatskaya et al. (2004) found that some firms offer to beat a rival's lower price by some percentage of the rival's price, and we note that Asda, a supermarket in the UK, recently promised to beat its rival's price by $10 \%$ regardless of whose price was lower. Analyses of these alternative types of low-price guarantees, and when managers might want to offer them, is beyond the scope of this paper.

Acknowledgements We gratefully acknowledge the financial support of the UK Economic and Social Research Council (ESRC). We thank participants at the 2011 annual meeting of the Chief Competition Economist of the European Competition Network, the UK Office of Fair Trading, and the 2012 International Industrial Organization Conference for helpful comments. The usual disclaimer applies.

Open Access This article is distributed under the terms of the Creative Commons Attribution License which permits any use, distribution, and reproduction in any medium, provided the original author(s) and the source are credited.

\section{Appendix}

In this Appendix, we characterize the set of prices $P_{x}$ for which the net gain from group A consumers in Table 1 outweighs any net loss from group B consumers in Table 1 when moving from a regime of uniform pricing to a regime of price matching. We also demonstrate the existence of a lower bound on $P_{x}, P_{L}^{P M}$, which is less than $P_{B}$, and an upper bound on $P_{x}, P_{H}^{P M}$, which is between $P_{U}$ and $P_{A}$, such that for all values of $P_{x}$ between $P_{L}^{P M}$ and $P_{H}^{P M}$, the firm's profit under price matching will be higher than that under uniform pricing.

To compute $P_{L}^{P M}\left(P_{x}\right)$ and $P_{H}^{P M}\left(P_{x}\right)$, we define $\Theta\left(P_{i} ; P_{x}\right)$ as:

$$
\begin{aligned}
\Theta\left(P_{i} ; P_{x}\right) \equiv & \left(P_{A}-c\right) D_{A}\left(P_{A} ; P_{x}\right)+\left(P_{i}-c\right) D_{B}\left(P_{i} ; P_{x}\right) \\
& -\left(P_{U}-c\right) D_{A}\left(P_{U} ; P_{x}\right)-\left(P_{U}-c\right) D_{B}\left(P_{U} ; P_{x}\right) .
\end{aligned}
$$

Note that our assumption that profits are concave implies that $\Theta\left(P_{i} ; P_{x}\right)$ is concave in $P_{i}$.

Note also that (i) $\Theta\left(c ; P_{x}\right)<0$ (because at $P_{i}=c$, the second term is zero. Since the firm could have chosen $P_{U}=P_{A}$ under uniform pricing, but did not, it must therefore be the case that the sum of the third and fourth terms exceeds the first term); (ii) $\Theta\left(P_{B} ; P_{x}\right)>0$ (because the profit from direct price discrimination exceeds that from uniform pricing); (iii) $\Theta\left(P_{U} ; P_{x}\right)>0$ (because the second and fourth terms cancel out and the first term exceeds the third term); and (iv) $\Theta\left(P_{A} ; P_{x}\right)<0$ (because $P_{U}$ is the unique optimal uniform price). 
Fig. $3 \Theta\left(P_{i} ; P_{x}\right)$

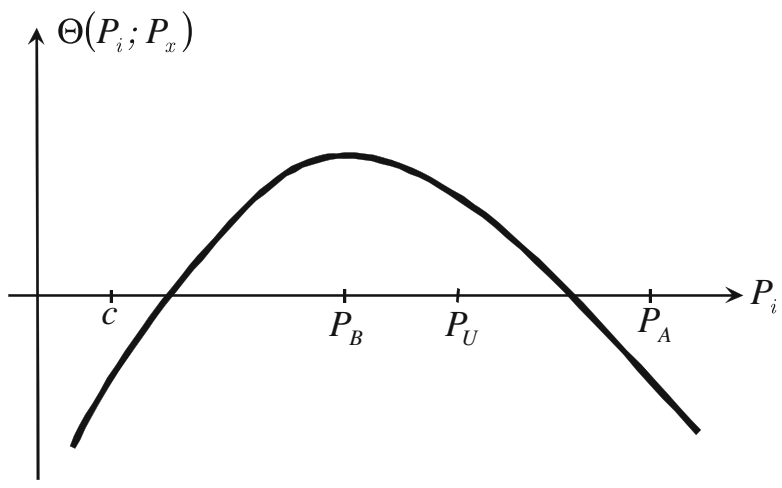

These observations, along with the concavity of $\Theta\left(P_{i} ; P_{x}\right)$, imply that for any given $P_{x}$, there are two solutions to $\Theta\left(P_{i} ; P_{x}\right)=0$. We denote these solutions by $P_{L}$ and $P_{H}$, respectively, where $c<P_{L}<P_{B}$ and $P_{U}<P_{H}<P_{A}$ (see Fig. 3). As $P_{x}$ varies along its domain, we can define the locus of such solutions by $P_{L}=P_{L}\left(P_{x}\right)$ and $P_{H}=P_{H}\left(P_{x}\right)$, respectively, with the properties that $c<P_{L}\left(P_{x}\right)<P_{B}\left(P_{x}\right)$ and $P_{U}\left(P_{x}\right)<P_{H}\left(P_{x}\right)<P_{A}\left(P_{x}\right)$.

Our assumptions imply that $P_{L}\left(P_{x}\right)$ and $P_{H}\left(P_{x}\right)$ are continuous in $P_{x}$, from which it follows that there exists $P_{x}$ such that $P_{x}=P_{L}\left(P_{x}\right)$, and similarly, there exists $P_{x}$ such that $P_{x}=P_{H}\left(P_{x}\right)$. If the solutions are unique, then we denote the $P_{x}$ that satisfies $P_{x}=P_{L}\left(P_{x}\right)$ by $P_{L}^{P M}$ and the $P_{x}$ that satisfies $P_{x}=$ $P_{H}\left(P_{x}\right)$ by $P_{H}^{P M}$. If the solutions are not unique, then we denote the smallest solution to $P_{x}=P_{L}\left(P_{x}\right)$ by $P_{L}^{P M}$, and the largest solution to $P_{x}=P_{H}\left(P_{x}\right)$ by $P_{H}^{P M}$ (see Fig. 4). In either case, whether these solutions are unique or not, we have the interpretation that for all $P_{x}<P_{L}^{P M}$ and $P_{x}>P_{H}^{P M}$, uniform pricing yields strictly higher profit than the profit that would arise under price matching.

Fig. 4 Solutions to $\Theta\left(P_{i} ; P_{x}\right)=0$ and $P_{i}=P_{x}$

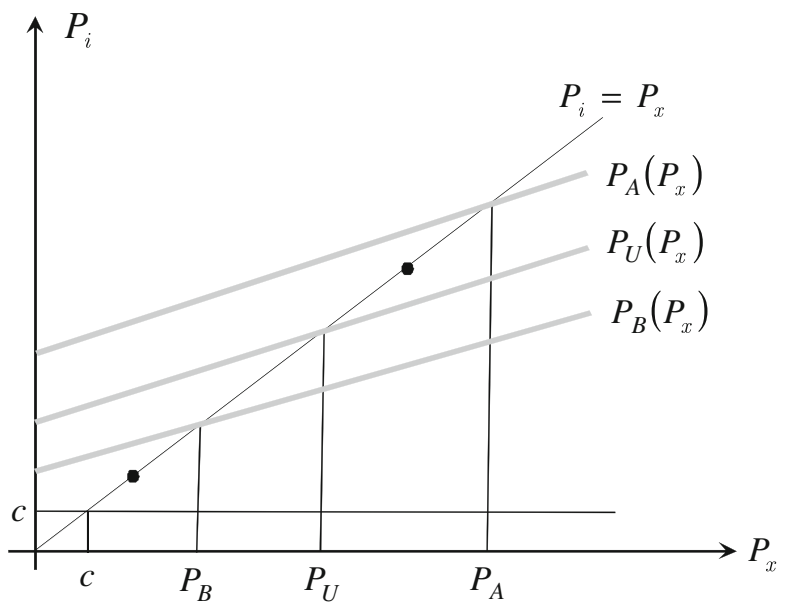




\section{References}

Aguirre, I., Cowan, S., \& Vickers, J. (2010). Monopoly price discrimination and demand curvature. American Economic Review, 100,1601-1615.

Arbatskaya, M., Hviid, M., \& Shaffer, G. (1999). Promises to match or beat the competition: Evidence from retail tire prices. Advances in Applied Microeconomics, 8, 123-138.

Arbatskaya, M., Hviid, M., \& Shaffer, G. (2004). On the incidence and variety of low-price guarantees. Journal of Law and Economics, 47, 307-332.

Arbatskaya, M., Hviid, M., \& Shaffer, G. (2006). On the use of low-price guarantees to discourage price-cutting: A test for pairwise-facilitation. International Journal of Industrial Organization, 24, 1139-1156.

Baye, M., \& Kovenock, D. (1994). How to sell a pickup truck: 'Beat-or-pay' advertisements as facilitating devices. International Journal of Industrial Organization, 12, 21-33.

Chen, Y. (1997). Paying customers to switch. Journal of Economics \& Management Strategy, 6, 877-897.

Chen, Y., \& Iyer, G. (2002). Customer addressability and customized pricing. Marketing Science, 21, 197-208.

Chen, Y., Narasimhan, C., \& Zhang, Z. J. (2001a). Consumer heterogeneity and competitive pricematching guarantees. Marketing Science, 20, 300-314.

Chen, Y., Narasimhan, C., \& Zhang, Z. J. (2001b). Individual marketing with imperfect targetability. Marketing Science, 20, 23-41.

Corts, K. (1995). On the robustness of the argument that price-matching is anti-competitive. Economics Letters, 47, 417-421.

Corts, K. (1997). On the competitive effects of price-matching policies. International Journal of Industrial Organization, 15, 283-299.

Corts, K. (1998). Third degree price discrimination in oligopoly: All-out competition and strategic commitment. Rand Journal of Economics, 29, 306-323.

Coughlan, A., \& Shaffer, G. (2009). Price-matching guarantees, retail competition, and productline assortment. Marketing Science, 28, 580-588.

Desmet, P., \& Le Negard, E. (2005) Differential effects of price-beating versus price-matching guarantees on retailers' price image. Journal of Product \& Brand Management, 14, 393-399.

Dobson, P., \& Waterson, M. (2005). Chain-store pricing across local markets. Journal of Economics and Management Strategy, 14, 93-119.

Edlin, A. (1990). Price matching, a ploy for price discrimination resuscitates the law of one price. Mimeo, University of California at Berkeley.

Edlin, A. (1997). Do guaranteed-low-price policies guarantee high prices, and can antitrust rise to the challenge? Harvard Law Review, 111, 528-575.

Edlin, A., \& Emch, E. (1999). The welfare losses from price-matching policies. Journal of Industrial Economics, 47, 145-168.

Hay, G. (1982). Oligopoly, shared monopoly, and antitrust law. Cornell Law Review, 28, 439-481.

Hess, J., \& Gerstner, E. (1991). Price-matching policies: An empirical case. Managerial and Decision Economics, 12, 305-315.

Hviid, M., \& Shaffer, G. (1994). Do low-price guarantees facilitate collusion? Working paper \#9402, Department of Economics, University of Michigan.

Hviid, M., \& Shaffer, G. (1999). Hassle-costs, the Achilles heel of price-matching guarantees. Journal of Economics and Management Strategy, 8, 489-521.

Jain, S., \& Srivastava, J. (2000). An experimental and theoretical analysis of price-matching refund policies. Journal of Marketing Research, 37, 351-362.

Kukar-Kinney, M., \& Walters, R. G. (2003). Consumer perceptions of refund depth and competitive scope in price-matching guarantees: Effects on store patronage. Journal of Retailing, 2003, 153-160

Moorthy, S., \& Winter, R. (2006). Price-matching guarantees. Rand Journal of Economics, 37, 449-465.

Nalca, A., Boyaci, T., \& Ray, S. (2010). Competitive price-matching guarantees under imperfect store availability. Quantitative Marketing and Economics, 8, 275-300.

Png, I. P. L., \& Hirshleifer, D. (1987). Price discrimination through offers to match price. Journal of Business, 60, 365-383. 
Robinson, J. (1933). The economics of imperfect competition. London: Macmillan.

Salop, S. (1986). Practices that (credibly) facilitate oligopoly coordination. In J. Stiglitz, \& F. Mathewson (Eds.), New developments in the analysis of market structure. Cambridge, MA: MIT Press.

Sargent, M. (1993). Economics upside down: Low-price guarantees as mechanisms for facilitating tacit collusion. University of Pennsylvania Law Review, 141, 2055-2118.

Schmalensee, R. (1981). Output and welfare implications of monopolistic third-degree price discrimination. American Economic Review, 71, 242-247.

Shaffer, G., \& Zhang, Z. (1995). Competitive coupon targeting. Marketing Science, 14, 395-416.

Shaffer, G., \& Zhang, J. (2002). Competitive one-to-one promotions. Management Science, 48, $1143-1160$.

Stole, L. (2007). Price discrimination and competition. In M. Armstrong, \& R. Porter (Eds.), Handbook of industrial organization (Vol. 3). Amsterdam, North Holland.

Tirole, J. (1988). The theory of industrial organization. Cambridge: MIT Press.

Varian, H. (1989). Price discrimination. In R. Schmalensee, \& R. D. Willig (Eds.), Handbook of industrial organization (Vol. 1). Amsterdam, North Holland.

Winter, R. A. (2008). Price-matching and meeting competition guarantees. Issues in competition law and policy (Vol. 2). ABA Section of Antitrust Law.

Zhang, Z. J. (1995). Price-matching policy and the principle of minimum differentiation. Journal of Industrial Economics, 43, 287-299. 